\title{
Are Certified Breast Centers Cost-Effective?
}

\author{
Matthias W. Beckmann Mayada R. Bani Christian R. Loehberg Thomas Hildebrandt \\ Michael G. Schrauder Stefanie Wagner Peter A. Fasching Michael Patrick Lux
}

University Breast Center of Franconia, University of Erlangen, Germany

\section{Key Words}

Breast center - Breast cancer - Certification .

Accreditation · Cost-effectiveness analysis

\section{Summary}

The German health care system has entered an era of specialist centers and certification. Hospitals are required to introduce quality management with external monitoring, refining and improving their quality of treatment. These statutory requirements can only be met through specialization, centralization, and establishing centers and networks with internal and external interdisciplinary collaboration. The breast centers certified according to the criteria of the German Cancer Society (DKG) and German Society for Mastology (DGS) are pioneers here. Simultaneously, there are increasing demands for more cost-effective medical services despite limited resources - making economic analysis of health care provision necessary. Few economic studies of the centers and certification system have been conducted, however. General long-term quality data, particularly for results, are not yet available from certified breast centers. At present, a certified breast center is not itself a proven independent prognostic parameter for treatment results. However, the individual criteria required for breast center certification show a significant positive influence on clinical efficacy. Certified breast centers involve substantial extra costs that are not reimbursed by funding bodies, so the slightest potential benefit for patients from certified centers already appears cost-effective. When the actual costs, currently usually subsidized by other departments, are considered, it is unclear whether certified breast centers remain cost-effective.

\author{
Schlüsselwörter \\ Brustzentrum · Mammakarzinom · Zertifizierung · \\ Akkreditierung $\cdot$ Kosteneffektivitätsanalyse
}

\section{Zusammenfassung}

Das deutsche Gesundheitswesen erlebt das Zeitalter der Zentrumsbildung und Zertifizierung. Krankenhäuser müssen ein Qualitätsmanagement mit externer Überprüfung einführen und ihre Behandlungsqualität weiterentwickeln. Dieser gesetzliche Anspruch kann nur durch Spezialisierung, Zentralisierung sowie Zentrums- und Netzwerkbildung mit interner und externer Interdisziplinarität erbracht werden. Vorreiter sind die zertifizierten Brustzentren nach den Kriterien der Deutschen Krebsgesellschaft (DKG) und der Deutschen Gesellschaft für Senologie (DGS). Parallel zu dieser Entwicklung nehmen bei zunehmend begrenzten Ressourcen im Gesundheitswesen die Forderungen nach Kosteneffektivität von medizinischen Leistungen zu, welche gesundheitsökonomische Analysen notwendig machen. Sowohl Zentrumsbildung als auch das Zertifizierungswesen wurden jedoch aus gesundheitsökonomischer Sicht bisher wenig untersucht. Allgemeine Langzeitqualitätsdaten, insbesondere zur Ergebnisqualität, aus den zertifizierten Brustzentren liegen noch nicht vor. Aktuell ist das zertifizierte Brustzentrum selbst kein nachgewiesener, eigenständiger Prognoseparameter für das Therapieergebnis. Jedoch wurde für einzelne Kriterien, deren Erfüllung Grundlage der Zertifizierung von Brustzentren ist, ein signifikanter positiver Einfluss auf die klinische Effektivität nachgewiesen. Demgegenüber steht ein erheblicher finanzieller Mehraufwand für zertifizierte Brustzentren. Da dieser aktuell nicht zusätzlich durch die Kostenträger vergütet wird, ist beim kleinsten möglichen Benefit für die Patientin durch zertifizierte Zentrumsstrukturen bereits eine Kosteneffektivtät gegeben. Ob zertifizierte Brustzentren bei Betrachtung der tatsächlich anfallenden Kosten, welche zurzeit meist durch weitere Abteilungen quersubventioniert werden, kosteneffektiv bleiben, ist unklar.

\begin{tabular}{ll}
\hline KARGER & @ 2009 S. Karger GmbH, Freiburg \\
Fax +497614520714 & Accessible online at: \\
Information@Karger.de & www.karger.com/brc \\
www.karger.com &
\end{tabular}




\section{Introduction}

\section{Development of Certified Breast Centers}

The health care system is currently experiencing a wave of developments involving the establishment and certification of specialized centers. The starting point for this trend was the establishment of certified centers in the field of gynecological oncology. Certification of centers has been possible at the international level for several years. The European Society of Mastology (EUSOMA) guidelines on the requirements for a specialized breast unit deal with various aspects relating to breast carcinoma and form the basis for the Society's own accreditation system. The purpose is to establish high standards in the quality of patient care $[1,2]$. The criteria include standard items such as buildings, equipment, available specialists, processes and standards, services, data management, and internal auditing. The processes of accreditation and re-accreditation every 5 years require transparency in the quality of the results.

At the national level in Germany, a distinction is made between specific organ cancer centers, oncological centers, and comprehensive cancer centers, in accordance with the threelevel model used by the German Cancer Society (Deutsche Krebsgesellschaft, DKG) [3]. The first level is the organ cancer center. A total of 185 certified breast centers have already been established in Germany [4]. Criteria regarded as essential for an organ center include in particular independent management of the center [5]. Additional criteria are efficient organizational and decision-making plans for diagnosis and therapy, and resources for documentation at reception for patients and during treatment and follow-up. The specialist requirements for high quality in the provision of care for patients with the various carcinoma entities are set out in established guidelines. One of the basic goals of organ centers is to improve the quality of oncological care, and this is to be achieved by adequate diagnosis and a practical therapeutic sequence [5]. Additional goals include increased economic efficiency which is to be achieved by avoiding multiple examinations, ensuring a tight organizational structure using patient routing, and common purchasing (e.g., of drugs). The second level of the care provision structure, which is to be implemented in the near future, is that of oncological centers which comprise several organ cancer centers. In addition to the organ-specific catalogue of requirements, oncological centers have to provide further resources which are organized on an inter-organ basis and concentrated centrally $[3,5]$. The third level of the oncological care provision structure and center formation is represented by comprehensive cancer centers (CCCs) which involve close coordination of preclinical research and clinical oncology [5].

\section{Background to the Cost-Effectiveness of Medical Services} Up to the mid-1980s, only very few pharmacoeconomic studies were carried out, as adequate financial resources were available to finance the health care services provided [6]. However, health care costs in most countries are now increasing exponentially. The USA is the world leader with regard to health care expenditure, followed by countries such as Germany and Switzerland [6]. The Institute for the Future (IFTF) is an independent nonprofit research group. Its aims are to identify alarming trends and divergences that may affect the global population and the world economy. The IFTF estimates that health care expenditure will continue to grow annually at a rate of $6.5 \%$ [7]. The exponential increase in costs is explained in part by medical and technological progress and the associated expansion of diagnostic and therapeutic facilities. In addition, demographic developments in the industrialized countries are also regarded as being responsible for increased costs, due to the need to provide care for older people. This contrasts with declining income in the health care system due to the decline in the younger proportion of the population, as well as increasing unemployment [6]. The effect of these developments is that medical decisions are increasingly acquiring an additional dimension - that of cost assessment. The available financial resources have to be distributed in accordance with the services required and their effectiveness (value). This presupposes an analysis and evaluation of the requirements $[6,8]$. In numerous countries, this type of analysis is a firmly established component of health care policy. One of the best-known examples is the National Institute of Clinical Excellence (NICE), founded by the British government. A similar development has been seen in Germany. The IQWiG is an independent scientific institute that examines the usefulness and benefit of medical services for patients [9]. One way of evaluating a medical service is to use decision-making models for health care economics. In addition to the criterion of effectiveness, these incorporate the side effect profile, costs arising, resources needed, and the patients' quality of life [8]. The models and the results of the analysis are intended to allow economic and health care policy decisions to be taken in such a way as to allow equivalent health care services to be provided at lower cost to the general public, or higher-quality services at the same cost.

The purpose of a classic cost-effectiveness analysis is to identify decisions that will achieve a maximum of health gained with the use of the available resources. A natural unit on a one-dimensional scale is always used here - e.g., additional years of life gained. The question answered is whether the resources expended for a service or treatment produce more or less benefit than the same sum spent on an alternative service. In relation to certified breast centers, reference data such as the rate of breast-conserving therapy (BCT), complication rates, recurrence rates, and also the overall survival are conceivable. The cost side of the breast centers can be calculated using funding body analyses. Both certification and specialization require additional services and the provision of special structures, which are associated with an additional substantial increase in costs [10]. Many hospitals are already under eco- 
Table 1. Overview of studies reporting a positive influence on treatment results [12]

\begin{tabular}{|c|c|c|c|c|c|}
\hline & \multicolumn{2}{|c|}{$\begin{array}{l}\text { Hospital case } \\
\text { numbers }\end{array}$} & \multirow[t]{2}{*}{$\begin{array}{l}\text { Hospital } \\
\text { specialization }\end{array}$} & \multirow[t]{2}{*}{$\begin{array}{l}\text { Case numbers } \\
\text { per physician }\end{array}$} & \multirow[t]{2}{*}{$\begin{array}{l}\text { Specialized } \\
\text { physician }\end{array}$} \\
\hline & $\begin{array}{l}\text { short- } \\
\text { term }\end{array}$ & $\begin{array}{l}\text { long- } \\
\text { term }\end{array}$ & & & \\
\hline Pancreas & +++ & + & & + & \\
\hline Other gastrointestinal & ++ & & & & \\
\hline Pulmonary & ++ & & & & + \\
\hline Colorectal & ++ & ++ & & ++ & ++ \\
\hline Breast carcinoma & & + & & ++ & ++ \\
\hline Ovarian carcinoma & + & + & & ++ & \\
\hline Prostate & + & & + & & \\
\hline Lymphoma & & & + & & \\
\hline Testes & & ++ & + & & \\
\hline
\end{tabular}

+++: 5 or more studies; ++: $2-4$ studies; + : 1 study. nomic pressure. While the hospitals' budget is increasing annually by $0.64 \%$, in line with the increase in the amount of basic pay, actual costs are increasing by $8-9 \%$. The reasons for this include pay increases, reduced revenue due to strikes, increased value added tax, increasing quality assurance requirements, and enormous amounts of delayed investment. Gynecological oncology is also partly affected by additional aspects to a greater extent than other specialist disciplines. These include innovative treatment approaches (e.g., sentinel node biopsy, SNB) - reducing the numbers of major interventions carried out and leading to reduced revenue, while the cost of the facilities provided remains the same; increasing reductions in mean hospitalization periods; and a failure to reflect new diagnostic and treatment procedures that for ethical reasons need to be offered to patients more quickly than they are reimbursed by the innovation-hostile case rate system. This cost pressure contrasts with the additional costs accruing due to certification. The relevant calculations for high-quality care provision structures are largely lacking [11]. It is therefore essential to consider the value provided by a certified breast center - its effectiveness - and the costs required to achieve this, using a cost-effectiveness analysis.

\section{Considering the Effectiveness and Costs of Certified Centers}

\section{The Effectiveness Side of Certified Breast Centers}

It is argued in principle that specialization and the establishment of centers are ways of ensuring and improving the quality of diagnosis and therapy. As this hypothesis represents the principal argument used by health care policy makers and also by specialist societies, it requires closer examination. Only a few studies on this topic are available in the literature. In addition, most of these studies have clear limitations - e.g., no calculation of case numbers, a lack of control groups, and inadequate statistical analysis. No prospective studies are available. The establishment of centers and certification have never been directly investigated parameters; investigations have only studied the individual criteria that define a center. In addition, it needs to be taken into account that numerous other factors, which are not determined by the establishment of the center or certification, may also influence treatment results - e.g., the patient's distance from the hospital, insurance limitations, and control of referrals by physicians in private practice. Hillner et al. [12] conducted a meta-analysis using Medline-listed publications on the issue of whether specialization and the size of a hospital have an influence on the treatment results. A positive influence was demonstrated retrospectively for several parameters in connection with the various carcinoma entities (table 1). Breast centers are thus reported as being associated with clinical effectiveness for individual criteria - e.g., case numbers. In accordance with the specialist societies' guidelines, a certified breast center must treat at least 100 patients with a primary carcinoma per year. In relation to breast carcinoma, dependence on case numbers has generally only been reported as a positive short-term effect in connection with curative operations [12]. In the longer term, this effect was moderate.

In the database of the Cancer Surveillance Program in Los Angeles, complete datasets were available for 29,666 patients with breast carcinoma. The treatment results were analyzed retrospectively in relation to age, ethnicity, tumor stage, surgical technique, case numbers per surgeon, and case numbers per hospital [13]. The 5-year survival rate improved significantly from 75 to $84 \%$ with increasing numbers of cases at a hospital. In addition, specialized centers were examined. As these were nominated by the National Cancer Institute, they can be regarded as comparable with certified breast centers. The evaluation of the overall survival using univariate analysis showed no significant difference between specialized centers and non-specialized centers (5-year survival 77 vs. $80 \%$; $\mathrm{p}=0.086)$. In the multivariate analysis, only a trend toward moderately improved survival was seen, with a relative risk of 
1.12 (95\% confidence interval (CI) 0.97-1.29). Du Bois et al. [14] retrospectively analyzed the care provision structure for breast carcinoma in the German federal state of Hesse. The rate of BCT was selected as a parameter for process quality. The relative risk of receiving a mastectomy was $25 \%$ higher in hospitals with fewer than 50 operations per year in comparison with those with more than 150 operations (relative risk (RR) 1.26; 95\% CI 1.11-1.25). This contrasts with the most recent overview of care provision in Germany published by Augurzky et al. [15] using data from the Federal Office of Statistics for 2007. This showed average case numbers of 126 breast carcinomas per hospital in Germany, but ranging from an average of 17 in small institutions and 74 in medium-sized ones to 658 in large university hospitals.

Certified breast centers are required to have surgeons who are specially trained in breast carcinoma surgery. Neuner et al. [16] showed, using a retrospective analysis of 8,105 patients with Medicare insurance, that with increasing case numbers per surgeon, there were significant increases in the rate of hormone receptor analyses $(\mathrm{p}=0.044)$, the $\mathrm{BCT}$ rate $(\mathrm{p}<0.001)$, and the rate of axillary dissections during mastectomy $(\mathrm{p}<0.001)$. Comparable associations have also been reported for SNB. Minimum numbers per year are prescribed for specialized and certified centers. An analysis of 2,255 patients who underwent operations conducted by 16 surgeons showed that when 3-6 SNBs per month were carried out, the success rate was $88.73 \%$. At more than 6 SNBs per month, the success rate rose to $97.81 \pm 0.40 \%$. The error rate declined markedly with increasing experience [17].

In the context of the analysis mentioned earlier, Skinner et al. [13] assessed the overall survival of breast carcinoma patients relative to case numbers per surgeon per year. The 5year survival increased significantly with increasing case numbers, from $75 \%$ at $1-5$ cases per year to $84 \%$ at over 15 cases per year $(\mathrm{p}<0.0001)$. Accordingly, the relative risk for overall survival increased statistically significantly by $16 \%$ (RR 0.84 ; 95\% CI 0.77-0.92). This underlines the necessity for surgeons to have adequate experience in the type of intervention, and this is usually only ensured at specialist centers with large numbers of cases. Skinner et al. [13] compared the results for oncological and general surgeons among 29,666 patients with breast carcinoma. A $23 \%$ higher overall survival rate was found in connection with specialization and when treatment was carried out by an oncological surgeon (RR 0.77; 95\% CI 0.67-0.88; $\mathrm{p}<0.0001$ ).

Another aspect of specialized centers is that they offer clinical studies. Certified breast centers are required to carry out full documentation, conduct analyses of treatment results, and include at least $30 \%$ of their patients in clinical studies. A clear difference between hospitals that conducted clinical studies and those not participating in studies (HR 1.71; 95\% CI 1.2-2.5) was shown using the example of the survival rate in patients with ovarian carcinoma, based on a German survey including 165 hospitals and 476 patients with FIGO stages
I-IV [18]. After 2 years, $72 \%$ of the patients in research hospitals were still alive, in comparison with only $64 \%$ in nonresearch hospitals. The authors explain the difference on the one hand through the potentially greater benefit of the study treatment. On the other hand, research hospitals need to have established infrastructures that make participation in studies possible. By participating in studies, research centers gain experience with the standards and can also apply them to patients outside the framework of the research protocols.

In summary, the general case numbers, treated cases per individual physician, numbers of operations conducted by the individual surgeons, specialization of the hospital, specialization of the physicians, and participation in clinical studies all show a positive influence on morbidity and mortality rates. These parameters have to be present in the context of a certified center. However, there is still no conclusive evidence that a certified breast center achieves a better quality of results. The certified center itself is not yet a proven independent prognostic parameter relative to breast carcinoma. Initial data from Germany show that certified centers can achieve this, however. In a prospective multicenter study, Brucker et al. [19] introduced a national benchmarking system for specialized breast centers. In the period between 2003 and 2007, there was clear optimization of the defined quality indicators - e.g., preoperative diagnostic confirmation with punch biopsy or radiotherapy after BCT. The authors conclude that as a result of specialization, certification, and the introduction of benchmarking systems, the quality of care provided for patients with breast carcinoma in Germany has markedly improved in recent years. The initially defined quality indicators served at first as surrogate markers for the quality of the results. As the data accrue over the coming years, true indicators of outcome quality are to be introduced - the first of which, disease-free survival, is currently in preparation.

\section{The Cost Side of Certified Breast Centers}

On closer examination, it is clear that both the establishment of centers and the certification system in the health care system have so far hardly received any scientific investigation from an economic point of view. Only a few models are currently available for calculating costs for certified oncological centers. It is extremely difficult to provide precise calculations, particularly when preserving the boundaries between cross-sector care provision structures in which different financing models are used. Wagner et al. [11] investigated the expenditure and income structures of a breast center certified by the DKG/DGS and accredited by EUSOMA. For the cost analysis, stepwise fixed-cost coverage calculation was selected, which is based on separating costs into fixed and variable components (fig. 1). In addition, the overhead costs (e.g., for the central hospital administration) have to be taken into account, which are usually calculated according to the principle of sustainability on the basis of revenues and can amount to up to $20 \%$. After stepwise deduction of all relevant costs, and 


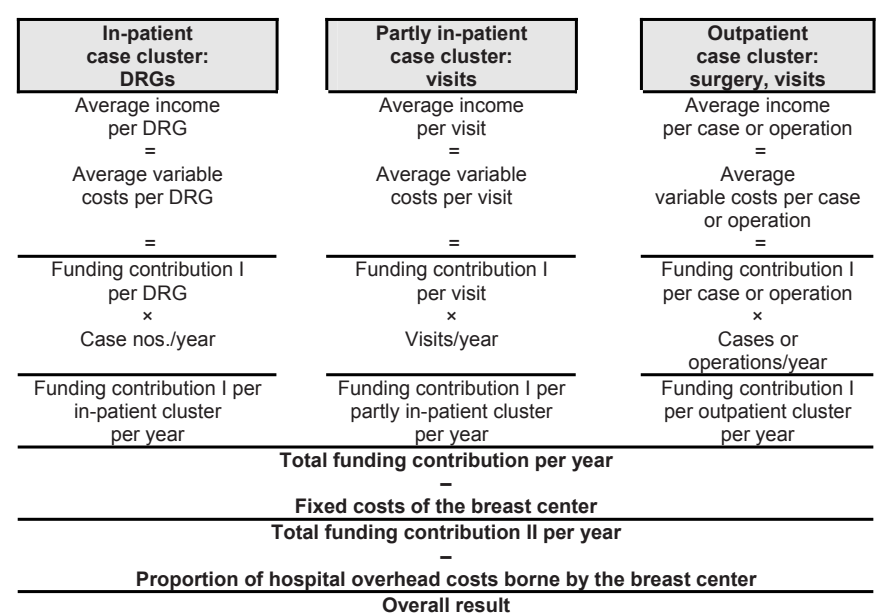

Fig. 1. Calculation model used at the University Breast Center for Franconia for 2005 [11]. DRG, diagnosis-related group.

taking into account income for the individual remuneration areas, it was found that for the breast center viewed as an isolated unit - i.e., an independent breast center without the surrounding hospital structure - there was an absolute loss of $€ 760,000$ (based on a basic case value of $€ 3,095.96$ for 2005). To cover real costs, additional revenue of $€ 1,288$ per calculated case would have been needed. The validity of these data was confirmed by Köckemann et al. [20] who calculated that an additional sum of $€ 1,646$ per patient with a first diagnosis of breast carcinoma would be needed to cover costs. Numerous other aspects were not taken into account here as they do not qualify for reimbursement - e.g., costs for certification and re-certification, further training, education, and continuing training, research, multiple documentation, coordination of the center, and additional support for patients and their families, and for providing infrastructure for interdisciplinary partners. These cost items do not arise in a hospital that is not specialized or certified. However, Augurzky et al. [15] showed in their study that numerous hospitals, independent of size, offer a broad, non-specialized range of treatments, leading to very low case numbers and potentially resulting in reduced quality when there is a lack of specialization in smaller hospitals.

Individual cost aspects in a certified breast center were investigated in another study by Wagner et al. [21]. Establishing the required quality management system alone, with subsequent certification and annual audits, resulted in additional costs of $€ 237,303$ over 4 years. The largest proportion here is represented by personnel costs at $€ 143,106$, arising due to personnel costs for quality management, documentation management, and preparations for certification or subsequent auditing. Furthermore, costs for certification fees, consultancy services, and travel and food expenses had to be taken into account. These costs for certification [10] are not matched by any direct income. Partial financing for these at least - e.g., via supplementary charges for the center - is not yet available nationally. This means that costs amounting to €237,303.45 fell to the breast center without compensation. This contrasts with demands from health care policy makers to provide a constantly optimized quality of treatment and results. The individual requirements include tumor documentation, for example. The availability of elementary data on findings, treatment courses, and disease courses, as well as continuous follow-up data, is intended to provide transparency in patient care. This also includes the education and further training of physicians and care teams, including research assistants, in order to ensure a high quality standard and the availability of the latest information in oncology. The common interdisciplinary organization with certification is intended to ensure a universal quality of treatment. Understandably, these additional services and structures create costs, but these bear no relation to the current reimbursement. The reason for this is the diagnosis-related group (DRG) system in Germany. The calculation of the average revenue for one case is carried out by distributing all relevant costs in the hospitals participating in the calculations to all of the cases, a process carried out by the Institute for the Hospital Remuneration System (Institut für das Entgeltsystem im Krankenhaus, InEK). However, only $37.5 \%$ of the data are derived from academic teaching hospitals. It is to be feared that this will lead to a distortion of the calculation basis and possible underfinancing of the certified centers, since the $40 \%$ of institutions offering basic provision and standard provision do not have to provide the personnel structure that a certified center requires [22]. In fact, a certified breast center is at present only capable of existing through being integrated into a hospital with cross-subsidization from other departmental areas.

\section{Are Breast Centers Now Cost-Effective? Summary and Conclusion}

Both health care policy in the context of the National Cancer Plan and the specialist societies are intensively supporting the process of establishing centers and providing certification. The certified breast centers have played a pioneering role in this development. However, the establishment of specialized breast centers has been associated with substantial expenditure - contrasting with the limited resources available in the health care system and the need to view medical services from the point of view of the economic aspects of health care.

There is therefore a justified demand for a cost-effectiveness analysis of certified breast centers. General long-term quality data, particularly with regard to the quality of results, are not available for the breast centers. Despite this, data are available regarding the effectiveness of the individual criteria that are required for certified breast centers - e.g., minimum number of cases at the center, case numbers per surgeon, study participation. On this basis, it can currently be assumed that clinical effectiveness exists. On the cost side, the prescribed 
structures give rise to a substantial financial burden for the centers. It is not currently clear whether the costs involved stand in a positive ratio to the effectiveness achieved for the patients. However, as the additional costs of certified breast centers are not currently reimbursed in the German health care system, so that there is no additional financial burden for the funding bodies, certified breast centers are necessarily cost-effective at present in purely economic terms and from the point of view of health care policy. When the additional financial outlay by the health insurance companies amounts to zero, the slightest increase in the effectiveness of any measure is already bound to represent a cost-effective step (i.e., identical costs for a qualitatively higher health care service).
However, the question arises of how long the corresponding effort required from the specialized centers in order to ensure the best possible treatment for breast cancer patients particularly in connection with providing, creating, and maintaining the structure of the center - can continue, when the financial resources available for the purpose remain constant or are completely absent.

\section{Conflict of Interest Statement}

The authors hereby confirm that no financial support from third parties was received in the context of preparing the present publication. Nor do any other conflicts of interest exist relating to the present publication.

\section{References}

$\checkmark 1$ Blamey RW, EUSOMA: The requirements of a specialist breast unit. Eur J Cancer 2000;36:22882293

2 Blamey RW, Cataliotti L, EUSOMA: The requirements of a specialist breast unit (revised version); in Perry N (ed): European Guidelines for Quality Assurance in Breast Cancer Screening and Diagnosis, 4th ed. Luxembourg, Office for Official Publications of the European Communities, 2006, pp. 343-354.

3 Beckmann MW, Adler G, Albers P, Bruns J, Ehninger G, Hauschild A, Neuhaus P, Schmiegel W, Schmitz S, Schmoll HJ, Weller M, Wiegel T, Bamberg M: Onkologie Dreistufenmodell optimiert Behandlung unter Kostendeckung. Wie die künftigen Strukturen der onkologischen Versorgung in Deutschland aussehen sollten. Dtsch Ärztebl 2007; 104:A-3004-3009.

4 www.onkozert.de.

5 Bamberg M: Konzeption für neue Versorgungsstrukturen in der Onkologie. Forum DKG 2006;7 34-36.

6 Porzsolt F: Klinische Ökonomik. Die ökonomische Bewertung von Gesundheitsleistungen aus der Sicht des Patienten; in Porzsolt F, Williams AR, Kaplan RM (eds): Klinische Ökonomik. Effektivität und Effizienz von Gesundheitsleistungen. Landsberg, Ecomed, 2003, pp. 17-40.

7 Institute for the Future: Health and Health Care 2010: The Forecast, the Challenge. San Francisco, Jossey-Bass, 2000.

8 Lux MP, Beckmann MW: Klinische Ökonomie in der gynäkologischen Onkologie. Frauenheilkd Aktuell 2008;2:35-41.
9 IQWiG: Methodik für die Bewertung von Verhältnissen zwischen Nutzen und Kosten im System der deutschen gesetzlichen Krankenversicherung. 2008; www.iqwig.de/download/08-01-24-Methoden_Kosten-Nutzen-Bewertung_Version_1_0.pdf.

10 Beckmann MW, Fasching PA, Lux MP, Bani MR, Schulz-Wendtland R, Ott O, Strnad V, Papadopoulos T, Helm G, Bach A, Rauch A, Marsch M, Wagner S: Brustzentrum: Zertifizierung, Qualität und Ökonomie. Klin Onkol 2007/2008;5:18-23.

11 Wagner S, Ganslandt T, Keiling CM, Jap D, Fasching PA, Lux MP, Beckmann MW: Ist ein Brustzentrum finanzierbar? - Ein Kalkulationsmodell für das Universitäts-Brustzentrum Franken (UBF). Geburtshilfe Frauenheilkd 2007;9:966-973.

12 Hillner BE, Smith TJ, Desch CE: Hospital and physician volume or specialization and outcomes in cancer treatment: importance in quality of cancer care. J Clin Oncol 2000;18:2327-2340.

13 Skinner KA, Helsper JT, Deapen D, Ye W, Sposto R: Breast cancer: do specialists make a difference? Ann Surg Oncol 2003;10:606-615.

14 Du Bois A, Miselwitz B, Stillger R, Jackisch C, Schwab R, Gnauert K, Hils R, Wagner U: Versorgungsstruktur und Qualität bei der Behandlung des Mammakarzinoms. Eine Untersuchung am Beispiel Daten aus Hessen 1996-2002. Geburtshilfe Frauenheilkd 2003;63:743-751.

15 Augurzky B, Krolop S, Römer K, Schwierz C, Kreienberg R: Frauenheilkunde und Geburtshilfe in Deutschland - eine Marktübersicht im akutstationären Sektor. Geburtsh Frauenheilkd 2009;69: 146-150.

16 Neuner JM, Gilligan MA, Sparapani R, Laud PW, Haggstrom D, Nattinger AB: Decentralization of breast cancer surgery in the United States. Cancer 2004;101:1323-1329.
17 Cox CE, Salud CJ, Cantor A, Bass SS, Peltz ES, Ebert MD, Nguyen K, Reintgen DS: Learning curves for breast cancer sentinel lymph node mapping based on surgical volume analysis. J Am Coll Surg 2001;193:593-600.

18 Du Bois A, Rochon J, Lamparter C, Pfisterer J; AGO Organkommission OVAR: Welchen Einfluss haben Klinikmerkmale auf die Prognose beim Ovarialkarzinom in Deutschland? Zentralbl Gynäkol 2005;127:18-30.

19 Brucker SY, Schumacher C, Sohn C, Rezai M, Bamberg M, Wallwiener D; Steering Committee: Benchmarking the quality of breast cancer care in a nationwide voluntary system: the first five-year results (2003-2007) from Germany as a proof of concept. BMC Cancer 2008;8:358.

20 Köckemann M, Lillteicher F: Entgeltverhandlungen 2007 - folgt das Geld der Qualität? Die bislang ausgebliebene Finanzierung zusätzlicher Strukturqualität von Brustzentren in NordrheinWestfalen. Krankenhaus 2007;5:439-445.

-21 Wagner S, Bani MR, Fasching PA, Schrauder MG, Löhberg CR, Beckmann MW, Lux MP: Ist ein Brustzentrum finanzierbar? - Berechnung einzelner Leistungen am Beispiel des Universitäts-Brustzentrums Franken (UBF). Geburtshilfe Frauenheilkd 2008;68:1178-1183.

22 Beckmann MW, Bechtold I, Debus G, Feige A, Frobenius W, Kiesel L, Lux MP, Sehouli J, Solomayer E, Steiner E, Wagner S, Schwenzer T, Kreienberg R, Wallwiener D: Ist die zukünftige Finanzierung von medizinischer Qualität noch gesichert? Bericht der Finanzierungskommission der DGGG e.V. - Teil I. Geburtshilfe Frauenheilkd 2008;68:1204-1214. 